F. W. Rossi ${ }^{1,2}$, F. Napolitano ${ }^{1}$, V. Pucino ${ }^{3}$, G. Capua ${ }^{4}$, D. Bianchedi ${ }^{4}$, F. Braconaro ${ }^{4}$, A. DE PAUlis ${ }^{1,2}$

\title{
Drug use and abuse and the risk of adverse events in soccer players: results from a survey in Italian second league players
}

${ }^{1}$ Department of Translational Medical Sciences, Center for Basic and Clinical Immunology Research (CISI), University of Naples Federico II, Naples, Italy

${ }^{2}$ WAO Center of Excellence ${ }^{3}$ College of Medical and Dental Sciences, Institute of Inflammation and Ageing, University of Birmingham, Birmingham, United Kingdom ${ }^{4}$ Anti-doping and Health Care Committee of "Federazione Italiana Giuoco Calcio", Rome, Italy

\section{KEY WORDS}

Drug abuse; adverse events; soccer players; $A Q U A^{\odot}$; sport; anaphylaxis; urticaria-angioedema; NSAIDs.

\section{Corresponding author}

Francesca Wanda Rossi

Department of Translational

Medical Sciences

Center for Basic and Clinical

Immunology Research (CISI)

University of Naples Federico II

via S. Pansini 5

80131 Naples, Italy

E-mail: francescawanda.rossi@unina.it

Doi

10.23822/EurAnnACI.1764-1489.163

\begin{abstract}
Summary
Objective. Drug use in athletes has been frequently investigated in the last three decades, especially regarding its misuse for doping. However, little is known about the use of permitted drugs for medical purposes and less studies have investigated the relationship between adverse drugs reactions (ADRs) and sports. Methods. An observational cross-sectional investigation analyzing a group of second league soccer players (the second-highest division in Italy) was performed. Anamnestic and physical examinations as well as a validated questionnaire (AQUA $\left.{ }^{\odot}\right)$ were performed in a group of 378 Italian second league soccer players. Results. Most players (91.8\%) reported the use of NSAIDs in the previous year, and one third of them were regular users. Analgesics were used in $64 \%$ of the players, while $52.1 \%$ had taken antibiotics in the previous year. $29.20 \%$ of players used intraarticular treatments in the previous year. In 7,4\% of players, an ADRs was reported: 3,47\% reacted to NSAIDs, 2,6\% to antibiotics, $1,05 \%$ to analgesics and 1 of them to supplements. For intra-articular injections, only 2 players experienced ADRs. One quarter of players experienced reactions as urticaria-angioedema syndrome or more severe conditions as bronchospasm or anaphylaxis. Conclusions. This study shows that drug misuselabuse in soccer is a real matter of debate, especially with regards to NSAIDs, exposing athletes to predictable and/or unpredictable risks for their health.
\end{abstract}

\section{Introduction}

In the last three decades, drug use in sports has been frequently investigated (1). The use of drugs not for medical purposes but as performance enhancers is widely known as "doping". The first official ban of performance enhancing drugs dates back to 1928 as the usage of "stimulating substances" was forbidden by the International Amateur Athletic Federation (2). The World Anti-Doping Agency has prohibited through the years the use of many substances which result in gaining advantage in performance, a risk for health, or in violating the "spirit of sport" (3). The Doping practice has "ancient" roots: the employment of performance-enhancing remedies goes back to Ancient Olympics (4). Several studies have been produced about misuse of drugs for doping in sports (5) while very little is known about the use of permitted drugs for medical purposes (6). A retrospective survey about the use of medication during FIFA World Cup 2014 in Brazil has shown that amongst top level players $67 \%$ took medications: 
F. W. Rossi, F. Napolitano, V. Pucino, et al.

$54.2 \%$ of them used Non-Steroidal Anti-Inflammatory Drugs (NSAIDs) while analgesics were taken by $12.6 \%$ and $\beta-2$ agonists by $0.5 \%$. Before each match, on average 0.8 medications per player were used (7). In Italy, an epidemiological study in 2007 showed that the regular assumption of permitted drugs has a high rate among professional soccer players. In the previous year, $92.6 \%$ of players assumed NSAIDs, $86.1 \%$ were current users, and $36 \%$ of them used analgesics. Moreover, $82.8 \%$ of the players used supplements, $28 \%$ of which were vitamins (8). No other investigations on this topic are available in the literature. Indeed, a limited range of studies has investigated adverse the rate of Adverse Drugs Reactions (ADRs) in agonistic sport athletes.

The World Health Organization (WHO) classifies hypersensitivity reactions to NSAIDs in type $\mathrm{B}$ adverse drug reaction (unpredictable and occurring in susceptible individuals) which differs from those predictable, based on pharmacological mechanisms and occurring in all individuals if a sufficient dose is applied (type A reactions) (9).

Based on the most recent EAACI/WAO nomenclature, hypersensitivity reactions to NSAIDs are further divided into 1) allergic-immunologically mediated (non-cross-reactive) and 2) non allergic-non immunologically mediated (cross-reactive) hypersensitivity reactions (9).

Stevenson et al. originally classified hypersensitivity reactions to NSAIDs accordingly to the clinical manifestation, the occurrence of an underlying disease, and a cross-reactivity with other inhibitors of the Cyclooxygenase (COX)-1 (10). A not immunological reaction is responsible of the hypersensitive to chemically nonrelated NSAIDs, sharing the common property of COX-1 enzyme inhibition and is called the 'cross-reactive' type of NSAIDs hypersensitivity. On the other hand, hypersensitivity symptoms that occur only after the ingestion of a single, specific NSAID (or belonging to the same chemical group), are considered immunologically mediated and defined as "allergic hypersensitivity reactions". The putative immunological (IgE or T-cell mediated) or nonimmunological (cross-reactive) mechanism is defined on the basis of the patient reaction and/ or the timing (11).

According to WAO, drug allergy is a relatively uncommon event, which represents less than $10 \%$ of all ADRs. It is responsible for $1 \%$ to $2 \%$ of all hospital admissions and $3 \%$ to $5 \%$ of hospitalized patients (12), although the true incidence of drug allergy in the community is still unknown. There are many risk factors for drug allergy, and they may be both drug related, and host related. Among the drug related factors, the degree of exposure in terms of dose, duration, and frequency of assumption should be considered (13). The aim of our work was to establish the prevalence of use of permitted drugs in a cohort of Italian professional soccer players as well as to investigate on its related ADRs rate.

\section{Study design and subjects}

The study was designed as an observational cross-sectional investigation analyzing a group of second league soccer players (the second-highest division in Italy). Players were consecutively enrolled during medical checkup performed training sessions. No particular criteria of inclusion and/or exclusion were chosen for the study enrollment. All subjects were enrolled from July 2015 to May 2016: each subject agreed to participate in the study and consent form was obtained.

\section{Materials and methods}

On a group of 378 Italian second league soccer players, anamnestic and physical examinations were performed with specific questionnaires being administered.

Anamnestic evaluation was focused on personal and family history of chronic diseases and on physical activities habits. A validated self-report Allergy Questionnaire for Athletes $\left(\mathrm{AQUA}^{\odot}\right)(14)$, with additional questions pertaining to training history and drug use habits, translated into the 5 main European languages (English, Italian, French, Spanish and German) was fulfilled by players. It included 4 different sections: 1) identity - including sociodemographic data such as gender, age and place of birth;2) physical activity history frequency in hours per week of training activity, numbers of years regarding the competitive practice and injuries occurring in career and in last year; 3) pharmacological anamnesis - investigating details on the therapeutic schemes used for traumas and for other common pathologies, players' own use of drugs or about recreational drugs; 4) ADRs - including details about the drug taken, type of reaction (localized or systemic reaction).

Continuous variables are presented as mean (standard deviation), and categorical variables are shown as frequencies and percentages. The independent contribution of several factors (role and age of the player, weekly hours of training, number of training sessions, body mass index) on permitted drug use was assessed using a multivariate general linear model.

\section{Results}

The characteristics of the study population (378 Italian second league soccer players) are shown in table I: they were all male individuals with a mean age of $24.8( \pm 5.4)$ years and a mean sport duration of activity of 12.1 years. The mean age at the beginning of professional activity was 10.4 years (range 4.0-18.0 years). The amount of physical activity usually performed was > 9 hours per week. About sport injures, $84.8 \%$ of players experienced a major injury at least once throughout the whole career: only in $38 \%$ the injury occurred during sport activity in the previous 12 months. 
Table I - Characteristics of Italian Serie B football players.

\begin{tabular}{ll}
\hline & Italian Serie B football players group \\
\hline Age, years \pm SD & $24.8 \pm 5.4$ \\
\hline $\begin{array}{l}\text { Gender, n (\%) } \\
\text { Male }\end{array}$ & $378(100 \%)$ \\
\hline $\begin{array}{l}\text { Race } \\
\text { African American }\end{array}$ & $17(4.5 \%)$ \\
$\begin{array}{l}\text { Caucasian } \\
\text { Hispanic-Latino }\end{array}$ & $326(86.2 \%)$ \\
\hline $\begin{array}{l}\text { BMI } \pm \text { SD Kg/m } \\
\text { MDSA, years } \pm \text { SD }\end{array}$ & $22.0 \pm 1.5 \%)$ \\
\hline $\begin{array}{l}\text { Mours/week n }(\%) \\
<3 \text { hrs }\end{array}$ & $0(0 \%)$ \\
3-7 hrs & $11(2.9 \%)$ \\
$>7$ hrs & $367(97.1 \%)$ \\
\hline
\end{tabular}

Muscle, tendon, ligament and meniscus injuries were found in $62.5 \%, 21.4 \%, 28.6 \%$, and $24.3 \%$, respectively. In $55.7 \%$ of injuried players, muscular lesions were experienced only once in their career and in $21 \%$ in the previous year. Tendon lesions occurred in $74 \%$ once in the sport career, in $26 \%$ more than once through the years and $9 \%$ in the previous year. Ligament injuries occurred in $65.2 \%$ of players once throughout career, in $34.8 \%$ more than once and in $12 \%$ in the previous year. Meniscus damage was experienced in $66.7 \%$ only once, while more than once in $33.3 \%$ with $15 \%$ being affected in the previous year (table II). Most players (91\%) reported the use of NSAIDs in the previous year, and about one third of them were regular users, defined as $>30$ days/year consumers (table III). Analgesics were used in $64 \%$ of the players, while $52.1 \%$ had taken antibiotics in the previous year. The drugs used in the previous year are summarised in table 3: 33,7\% referred NSAIDs use lasting more than 30 days in the whole year, while 75 players $(19.85 \%$ of the whole study population) were currently using analgesics. Almost all players reported the use of supplements (98\%) and among users on a daily basis (80\%), $25 \%$ of subjects used supplements more than once a day. Out of 110 players (29.2\%) using intraarticular treatments 34 (31\%) used platelet gel at least once and 15 of them more than once in the previous year. In total, hyaluronic acid was administered to 84 players (22.3\%) and in 39 of them in more than one course of treatment. $2 \%$ of players treated with steroidal intraarticular therapy and one third of them underwent the treatment more than once in the previous year. Other drugs (i.e., anaesthetics) were administered to $2.8 \%$ of the players (table III).
Table II - Injuries in soccer players.

\begin{tabular}{ll}
\hline Type of injuries $\mathbf{n}(\%)$ & Yes \\
\hline Sport injuries & $321(84.8 \%)$ \\
\hline & \\
Muscle injury & $201(62.5 \%)$ \\
Frequency: & $112(55.7 \%)$ \\
1 time & $89(44.3 \%)$ \\
$>1$ time & $69(21.4 \%)$ \\
Tendon injury & $51(74 \%)$ \\
Frequency: & $18(26 \%)$ \\
1 time & \\
$>1$ time & $92(28.6 \%)$ \\
Ligament injury & $60(65.2 \%)$ \\
Frequency: & $32(34.8 \%)$ \\
1 time & 1 time \\
Meniscus injury & $78(24.3 \%)$ \\
Frequency: & $52(66.7 \%)$ \\
1 time & 1 time
\end{tabular}

Injuries occurred during the previous year

$\begin{array}{lc}\text { Tot } & 122(38 \%) \\ \text { Muscles } & 67(21 \%) \\ \text { Tendon } & 29(9 \%) \\ \text { Ligament } & 38(12 \%) \\ \text { Meniscus } & 48(15 \%)\end{array}$

Other injuries

Upper limb

$48(15 \%)$

Shoulder

$18(5.5 \%)$

Elbow

$6(1.9 \%)$

Hand

$18(5.6 \%)$

Lower limb

$58(18 \%)$

Hip

$18(5.6 \%)$

Knee

$23(7.3 \%)$

Ankle

$26(8.1 \%)$

Foot

$15(4.6 \%)$

Spine

$18(5.6 \%)$

At least one ADR was reported in 7,9\% of players: $3,5 \%$ reacted to NSAIDs, $2,6 \%$ to antibiotics, $1 \%$ to analgesics and one case was reported as a reaction to supplements (table IV). For intra-articular injections, only 2 players $(0.5 \%)$ experienced a knee effusion and a skin rash. 
Table III - Permitted drug use in soccer players in last years and frequency.

\begin{tabular}{lll}
\hline ADRs & n & (\%) \\
\hline Non-steroidal anti inflammatory & 13 & 3.5 \\
\hline Analgesics & 4 & 1 \\
\hline Antibiotics & 10 & 2.6 \\
\hline $\begin{array}{l}\text { Supplements (minerals, supplements, } \\
\text { vitamins) }\end{array}$ & 1 & 0.3 \\
\hline $\begin{array}{l}\text { Intraarticular (CCS, hyaluronic acids, } \\
\text { platelets gel) }\end{array}$ & 2 & 0.5 \\
\hline
\end{tabular}

Table IV - ADRs to permitted drug in soccer players.

\begin{tabular}{lll}
\hline Drug category & Users n (\%) & $\begin{array}{l}\text { Current (>30 d/y) } \\
\text { users n (\%) }\end{array}$ \\
\hline $\begin{array}{l}\text { Non-Steroidal } \\
\text { Anti Inflammatory } \\
\text { (NSAIDs) }\end{array}$ & $344(91 \%)$ & $116(33.7 \%)$ \\
\hline Analgesics & $242(64 \%)$ & $75(31.8 \%)$ \\
\hline Antibiotics & $197(52,1 \%)$ & $11(5.6 \%)$ \\
\hline $\begin{array}{l}\text { Supplements (minerals, } \\
\text { supplements, vitamins) }\end{array}$ & $374(98.9 \%)$ & $302(80.7 \%$ daily $)$ \\
\hline $\begin{array}{l}\text { Topic-intraarticular } \\
\text { Drug }\end{array}$ & Users n (\%) & Current (>30 d/y) \\
\hline Platelet gel & $34(8.9 \%)$ & $15(44.1 \%)$ \\
\hline Hyaluronic acid & $84(22.3 \%)$ & $39(46.4 \%)$ \\
\hline Steroids & $8(2 \%)$ & $3(37.5 \%)$ \\
\hline Others & $11(2.8 \%)$ & $4(36.3 \%)$ \\
\hline
\end{tabular}

The largest number of ADRs may be predictable as non immunologic reactions while a non-negligible percentage is immunologically mediated drug hypersensitivity. In 30\% of the players, reactions as urticaria-angioedema syndrome or more severe conditions as bronchospasm or anaphylaxis (1 case reported) have been found (table V).

\section{Discussion}

Literature interest in relationship between physical activity, chronic inflammatory diseases and drug use is increasing. Particularly, we have previously showed how a regular and intense physical exercise could prevent or reduce the risk of developing a chronic inflammatory skin disease such as psoriasis in both non agonist as well as agonistic (Italian second soccer league) athletes $(15,16)$. However, information regarding drug use/abuse and related ADR are still limited. The data obtained in our survey show a significant use $(<90 \%)$ of permitted drugs among professional second league soccer players. The most frequently used drugs were NSAIDs: approximately, one third of the players had NSAIDs almost 1 time per month during the previous year. Antibiotics and analgesics were used less frequently. A regular use of supplements was observed in a great number of players (80\%): the identification of the chemical composition of the supplements was regretfully impossible due to the high number of products consumed. In agreement with a previous similar cross-sectional study, our data confirmed an ongoing tendency to abuse drugs (8), in our cohort of players independently from doctor's advice. In fact in most cases, the use and abuse of permitted drugs is not justified by acute or chronic diseases or events, or by appropriate medical prescription. It is also widely known that soccer determines an increasing number of traumas and injuries (17), especially when practiced at a competitive level. The highest rate of these events is usually restricted to the sport season, throughout fall, winter, and spring (18). Interestingly, our data indicate that $80 \%$ of players reported drugs intake during their whole career, but less than a half

Table $V$ - Type of ARDs to permitted drug in soccer players.

\begin{tabular}{llccc}
\hline Type of ADRs n (\%) & Non Immunomediated & OAS & Bronchospasm & Anaphylaxis \\
\hline $\begin{array}{l}\text { Non-steroidal } \\
\text { anti inflammatory }\end{array}$ & $7(54 \%)$ & $3(23 \%)$ & $2(15.5 \%)$ & $1(7.5 \%)$ \\
\hline Analgesics & $3(75 \%)$ & $1(25 \%)$ & $0(0 \%)$ & $0(0 \%)$ \\
\hline Antibiotics & $8(80 \%)$ & $2(20 \%)$ & $0(0 \%)$ & $0(0 \%)$ \\
\hline $\begin{array}{l}\text { Supplements (minerals, } \\
\text { supplements, vitamins) }\end{array}$ & $1(100 \%)$ & $0(0 \%)$ & $0(0 \%)$ & $0(0 \%)$ \\
\hline $\begin{array}{l}\text { Intraarticular } \\
\begin{array}{l}\text { CCS, hyaluronic acids, } \\
\text { platelets gel) }\end{array}\end{array}$ & $1(0.3 \%)$ & $1(0.3 \%)$ & $0(0 \%)$ & $0(0 \%)$ \\
\hline
\end{tabular}


of them had suffered injuries during the previous year. Clearly, such a wide use of NSAIDs and analgesics among elite soccer players is justified by real necessity but likely becomes a habit of self-administration, especially in terms of prolonged duration of treatment, combo therapy and/or prophylactic use devoid of any medical rationale. Actually, self drug administration appears to be common practice among athletes and often drugs are taken spontaneously, without seeking medical advice (7). This happens for extended periods (19) of time and beyond the recommended doses, furthermore in associations with many other drugs without given therapeutic evidences. Our data clearly show that NSAIDs and painkiller as well as of supplements are the classes of drugs that fit into the picture of self-administration. Obviously, this attitude exposes the players to an increased ADRs risk, especially following incorrect drugs intake and combination. Increased risk of ADRs is not predictable reactions i.e., those related to the substance pharmacologic action -, but is also unfortunately unpredictable because reactions depend on genetic factors, patients' immunological response, etc.

As a matter of fact, many ADRs (30\%) are unpredictable and immune-mediated. It has been reported an increased incidence ADRs following an inappropriate use of NSAIDs (13). Moreover, this kind of reaction not only exposes to clinical manifestations or organ-specific symptoms such as urticaria-angioedema (23\%), prurigo, rhinitis, but also to life threatening systemic manifestations such as bronchial spasm (6.6\%), hypotension and anaphylaxis (in our cohort observed in 1 case).

As observed for systemic drugs our analysis highlights use and abuse of intra-articular substances as well. Intraarticular injections are commonly used in practice to treat chronic pain due to traumatic or degenerative diseases. Use of intraarticular drugs among soccer players has not been fully investigated and only few cases are reported $(20,21)$. In our cohort one third of soccer players $(29.2 \%)$ were treated at least once with intraarticular injections and $9.3 \%$ used intraarticular drugs in the previous year. Although few ADRs were attributed to intraarticular treatment, $7-9 \%$ of patients experienced, especially during the first and second cycle, local ADRs like flares, effusions (22), skin rashes (23) and skin necrosis (24). Local reactions occurred significantly more often in patients who received more than one course of treatment than in patients who had received only a single course of treatment (25). Moreover, serious systemic adverse events like septic arthritis, disorders of the nervous system, of the circulatory (26) and musculoskeletal system (27) have been described. Episodes of anaphylactic shock were also reported (28). In our study, we observed only 2 cases ( $0.6 \%$ of all cohort) of mild ADRs related to intraarticular drug use.

In the last 30 years, doping has been largely described and has taken a center stage in the public attention. This has raised a significant awareness of the problem and has led to the devel- opment of detection methods for regular monitoring in sports. Nevertheless, this drug misuse/abuse still happens in professional and amateur sports not only involving medications considered as performance-enhancing. Our survey shows a better knowledge and raised awareness about the problem of sport medicalization, now perceived as a problem but only for its impact on performance and sport activity. The awareness about doping harming athletes' health is still not fully developed. This finding is enforced by data showing that drug use/abuse has not changed much in the last decade (8).

An effort by sport institutions is warranted in raising awareness in the sport community overuse/abuse of drugs and their impact on the athletic performance and on the risks and implications for the athlete's health. The education should start likely at school level, in pediatric and young adult age, when the recreational aim of sport should go at the same pace with the educational purpose.

\section{Conclusions}

This study shows that drug misuse/abuse in professional soccer players is an emerging issue, especially with regards to NSAIDs, exposing athletes to predictable or/and unpredictable risks for their health. In the future, it is of crucial importance to foster the athlete's awareness of these problems through a continuous education, starting from the very beginning of sport practice.

\section{Conflict of interests}

The authors declare that they have no conflict of interests.

\section{References}

1. Noakes TD. Tainted Glory Doping and Athletic Performance. N Engl J Med 2004;351:847-849.

2. Anti-Doping History: IAAF Handbook 1927-1928.

3. WADA. World Anti-Doping Code 2021.

4. Yesalis CE, Bahrke MS. History of doping in sport. In: Performance-Enhancing Substances in Sport and Exercise, $1^{\text {st }} \mathrm{ed}$. Champaign, IL: Human Kinetics, 2002:p. 20.

5. World Health Organization. International drug monitoring: the role of national centres. World Health Organ Tech Rep Ser 1972;498:1-25.

6. Waddington I, Malcolm D, Roderick M. Drug use in English professional football. Br J Sports Med 2005;39:e18.

7. Vaso M, Weber A, Tscholl PM, et al. Use and abuse of medication during 2014 FIFA World Cup Brazil: a retrospective survey. BMJ Open 2015;10;5:e007608.

8. Taioli E. Use of permitted drugs in Italian professional soccer players. Br J Sports Med 2007;41:439-41.

9. Kowalski ML, Asero R, Bavbek S, et al. Classification and practical approach to the diagnosis and management of hypersensitivity to nonsteroidal anti-inflammatory drugs. Allergy 2013;68:1219-32.

10. Stevenson DD, Sanchez-Borges M, Szczeklik A. Classification of allergic and pseudoallergic reactions to drugs that inhibit cyclooxygenase enzymes. Ann Allergy Asthma Immunol 2001;87:177-180. 
11. Kowalski ML, Makowska JS, Blanca M, et al. Hypersensitivity to nonsteroidal anti-inflammatory drugs (NSAIDs) - classification, diagnosis and management: review of the EAACI/ENDA(\#) and GA2LEN/HANNA* Allergy 2011;66:818-829.

12. Thong BY, Tan TC. Epidemiology and risk factors for drug allergy. Br J Clin Pharmacol 2011;71:684-700.

13. Bousquet PJ, Demoly P, Romano A, et al. Global Allergy, Asthma European Network (GALEN) and Drug Allergy and Hypersensitivity Database (DAHD) and the European Network for Drug Allergy (ENDA) Pharmacovigilance of drug allergy and hypersensitivity using the ENDA-DAHD database and the GALEN platform. The Galenda project. Allergy 2009;64:194-203.

14. Bonini M, Braido F, Baiardini I. Allergy questionnaire for athletes. Development and validation. Med Sci Sports Exerc 2009;7:10341041.

15. Megna M, Lobasso A, Napolitano A, et al. Soccer helps in controlling the development of psoriasis in Italian second league players. J Eur Acad Dermatol Venereol 2017;31:e212-e214.

16. Balato N, Megna M, Palmisano F, et al. Psoriasis and sport: a new ally? J Eur Acad Dermatol Venereol 2015;29:515-20.

17. Junge $A$, Dvořák J. Injury surveillance in the World Football Tournaments 1998-2012. J Br J Sports Med 2013;47:782-8.

18. Junge A, Dvořák J. Football injuries during the 2014 FIFA World Cup. Br J Sports Med 2015;49 599-602.

19. Tscholl PM, Vaso M, Weber A, Dvořák J. High prevalence of medication use in professional football tournaments including the
World Cups between 2002 and 2014: a narrative review with a focus on NSAIDs. Br J Sports Med 2015;49:580-2.

20. Robinson P, Bollen SR. AJR Posterior ankle impingement in professional soccer players: effectiveness of sonographically guided therapy. Am J Roentgenol 2006;187:53-8.

21. Fredberg U, Bolvig L. Traumatic arthritis in sport. Scand J Med Sci Sports 2001;11:251-4.

22. Brandt KD, Block JA, Michalski JP, et al. Efficacy and Safety of Intraarticular Sodium Hyaluronate in Knee Osteoarthritis. Clin Orthop Relat Res 2001;385:130-143.

23. Peralta L, Morais P. Monomorphous papulopustular rash - a case study. Aust Fam Physician 2011;40:982-3.

24. Kim WB, Alhusayen RO. Skin Necrosis from Intra-articular Hyaluronic Acid Injection. J Cutan Med Surg 2015;9:182-84.

25. Leopold SS, Warme WJ, Pettis PD, Shott S. Increased frequency of acute local reaction to intra-articular hylan GF-20 (synvisc) in patients receiving more than one course of treatment. J Bone Joint Surg Am 2002:84:1619-23.

26. Jüni P, Reichenbach S, Trelle S, et al. Efficacy and Safety of Intraarticular Hylan or Hyaluronic Acids for Osteoarthritis of the Knee A Randomized Controlled Trial. Arthritis Rheum 2007;56:3610-19.

27. Mills SP, Charalambous CP, Hayton MJ. Bilateral rupture of the extensor pollicis longus tendon in a professional goalkeeper following steroid injections for extensor tenosynovitis. Hand Surg 2009;14:135-7.

28. Borderé A, Stockman A, Boone B, et al. A case of anaphylaxis caused by macrogol 3350 after injection of a corticosteroid. Contact Dermatitis 2012;67:376-8. 